\title{
Analysis on the Impact of Modern Information Technology upon the Professional Development of College English Teachers
}

\author{
Yong-mei LI* \\ Xi'an University of Technology, Xi'an Shaanxi 710054, China \\ ${ }^{*}$ Corresponding author
}

Keywords: Impact, Information technology, Foreign language teaching, Professional development.

\begin{abstract}
With the development of modern information technology, great changes have taken place in teaching concepts and teaching methods. This paper analyzed the opportunities and challenges faced by college English teachers in the information age and demonstrated how to use modern information technologies to innovate teaching and how to grasp opportunities to achieve their professional development. In order to improve teaching quality and promote professional development more effectively, college English teachers should keep up with the times and enrich the connotation of teachers' roles from all aspects.
\end{abstract}

\section{Introduction}

With the rapid development of higher education, people generally recognize the importance of building high quality teaching staff. Teachers' development includes the continuous improvement and development of their personal qualities and professional qualities. Building a high-quality teacher team is an important part of college English teaching and reform project, and it is also a prerequisite for improving college English teaching. The faculty in various universities is uneven, and the situation varies greatly in terms of teachers' age structure, educational structure, professional title structure, gender structure, as well as the types of universities and students' English proficiency. Therefore, the reasons that affect teachers' development are quite different. In general, the development of modern information technology has the most significant impact on the professional development of English teachers. China's National Plan for Medium and Long-term Education Reform and Development (2010-2020) clearly stated that we must speed up the process of education informationization. By 2020, we will basically build a digital education service system covering all levels of schools in urban and rural areas to promote the modernization of educational contents and teaching methods. Strengthen the construction of online teaching resources database, introduce international high-quality digital teaching resources and develop e-learning courses. Encourage students to learn actively, independently, and enhance their abilities to analyze and solve problems by using information technology.[1] A good teacher should be a smart teacher with the wisdom to learn, to live and to educate, who can help and guide students in all aspects. The development of modern information technology has made online teaching and smart classroom possible, and meanwhile put forward higher requirements for teachers' abilities and qualities. This has brought both opportunities and challenges for the development of English teachers' professional careers,

\section{Opportunities brought by Modern Information Technology}

According to the syllabus requirements of the Ministry of Education, the goal of college English teaching is to cultivate students' comprehensive English application skills, especially their listening and speaking skills, to improve their comprehensive cultural qualities and enhance their ability to learn independently. The requirements point out: "College English is guided by the theory of foreign language teaching, with English language knowledge and application skills, cross-cultural communication and learning strategies as the main content, and a teaching system integrating various teaching modes and teaching methods."[2] The development of modern information technology has 
provided a variety of flexible and varied teaching models for college English teachers, and provided opportunities for their professional development.

\section{Information Technology Helps Teachers Renew Ideas and Change Roles}

Education informationization is not only a process of in-depth fusion of informationization and teaching, but also a modern and advanced educational philosophy. In the context of information society, with the widespread use of internet technologies, new teaching models and teaching methods emerge constantly, such as distance education, online and offline, flipped classrooms, and smart classrooms, which prompts foreign language teachers to update their concepts and change their roles in order to adapt to the new requirements. Under the information-based teaching model, especially in learner-centered foreign language classes, teachers should change their roles by rationally using information technology. To be specific, teachers should switch from communicators of language knowledge in the past to cultivators of language skills and communicators of cultures; from leaders in teaching activities to facilitators, participants and students' collaborators; from single "teachers" to reflective researchers. Teachers cannot passively wait for others to send their research results and apply them to teaching without thinking.A teacher himself should be a researcher, and he should take the researcher's mentality into the process of teaching activities, examine and analyze the problems in teaching theory and teaching practice from the researcher's perspective, explore and summarize the reasons of the problems, thus creatively design and implement new and effective teaching modes. Education informationization is conducive to establishing new education concept, talent concept and methodology. Teachers should update their knowledge structure constantly to make information technology serve teaching better. For a long time, foreign language teachers have faced many problems, such as more hours, great stress, and less training opportunities. The integration of information technology into foreign language classrooms has fundamentally changed educational relations. Foreign language teachers are both creators and executors of educational and teaching activities as well as learners in the process. In the information society, knowledge is changing with each passing day. People must become life-long learners, this is not only the need for teaching work, but also the need for their own development. Education informationization provides a multi-channel platform for foreign language learning and teacher education, such as online universities, virtual communities, and MOOC. Teachers can both prepare lessons and facilitate "charging" themselves to improve their knowledge literacy, professional skills, and research capabilities.

\section{Modern Information Technology Provides Teachers with Powerful Support for Improving Teaching Quality}

With the development of modern information technology, the teaching modes and teaching methods that teachers can use are constantly emerging, such as: cyberspace, MOOC, micro class, flipped classroom, WeChat platform, microblog platform, smart classroom, and so on. These teaching modes and teaching methods can effectively help teachers improve the teaching quality. Take the flipped classroom as an example, to put it simply, flipped classroom is a classroom in which students watch the video posted on the internet that the teacher has produced before class. In the classroom, the students interact with the teacher to solve key and difficult problems in the learning process, and review, consolidate, and internalize the learned knowledge after class. College English is a language skill class. Its most important function is to communicate in English. The class interactions in flipped classroom can maximize this language exchange. Through classroom interactions, students' English presentation ability will be improved gradually.Teacher can ask students to answer questions in the preschool video; students can also ask teacher to answer difficult questions. "In the teaching activities, the teacher and the students interact fully, students are no longer passive recipients, and teacher is no longer merely knowledge imparter. Based on the reorganization of knowledge points in pre-course micro-videos, the teacher supplements learning resources such as blackboard-writing and electronic documents to meet students' various learning needs. The teacher also provides collective explanations based on the students' feedback on the network and eliminates most students' doubts and difficulties."[3] "Flipped classroom can liberate teachers from the tedious task of imparting 
knowledge, teachers have more time to answer students' doubts, which can help teachers develop personalized teaching and students cultivate their active learning ability."[4] Secondly, flipped classroom can improve learning efficiency. It leaves as much time as possible for classroom activities and reduces the teacher's lecture time. "In the flipped classroom model, the content taught in the classroom is completed before class through network, and the interaction between teachers and students in the classroom is enhanced on the basis of not reducing the imparting of basic knowledge. The time extension of teaching and learning is accomplished by maximizing 'prep time' to achieve a deep internalization of knowledge, and thus improve learning efficiency."[5] Furthermore, flipped classroom can improve students' ability to communicate in English. It can provide more opportunities for teacher-student interaction. In the classroom, questions, answers, and discussions all require language exchanges so that students can effectively exercise and improve their English expression abilities. In addition, students' communication and self-presentation in class can also enhance their learning enthusiasm and stimulate their potential to explore knowledge before class.

\section{Modern Information Technology Provides Teachers with Larger Development Space}

Teachers can use information technology to optimize teaching methods. Education informationization not only provides more resources and more opportunities for teachers' development, but also respects teachers' differences, encourages their personalized development, and allows them to participate in curriculum development more extensively and deeply. So teaching results will permeate more personal style. In the traditional English class, many students have gradually lost interest due to the invariable teaching model. The boring and abstraction of English learning has reduced students' confidence. However, with the aid of multimedia technology based on modern information technology, teachers can simulate real-life situations in their daily work, study, and life, which are closely related to the real life and make students feel like being in real situations. Multimedia technology can transform plane English into graphic language and dynamic video. Classroom contents can be displayed through images, videos, animations, sounds, etc., which combines listening, speaking, reading and writing together to make the classroom more appealing.

By using modern information technology, foreign language teachers can learn, collect and download teaching materials they need through the internet and a large number of learning platforms, design their own unique teaching models to improve students' English proficiency, cultural accomplishments and knowledge literacy through various means. In teaching activities, the stereotyped teaching model is hard to arouse students' interests. The wider a teacher's knowledge area, the stronger the personality charm, the more advanced and diversified the teaching methods, the more comprehensive influence he has on the students, and the better the teaching effect will be achieved. So modern Information technology will provide a broader space for teachers' personalized development.

\section{Challenges Brought by Modern Information Technology}

Opportunities always coexist with challenges. Education informationization has promoted the innovation of education and brought great opportunities to the professional development of college English teachers, and meanwhile it also poses great challenges and puts forward new requirements for them.

\section{Impact on Teachers' Traditional Education Concept and Role Positioning}

Education informatization subverts teachers' traditional ideas and concepts. "spreading morality, imparting knowledge and explaining puzzles" has always been the best interpretation of the role of a teacher. For thousands of years, it has been used as a measure of whether teachers are qualified or not. Under this traditional teaching concept, a set of fixed teaching modes has been formed, namely, teacher-centered class. Teachers control the teaching contents and teaching progress, mainly teach vocabulary, grammar, chapters and exercises, students passively accept knowledge. Students' motivation, learning methods and strategies have not received due attention. With the help of modern 
information technology, teachers can adopt many teaching methods and means, such as flipped classrooms, cyberspace, MOOC platforms, and so on. If teachers have been educating people with traditional educational ideas and concepts, how can they cultivate "modern people" that adapt to the needs of the knowledge-based economy and information society, and "modern people" who are in line with international standards? Therefore, teachers must abandon the old and outdated ideas and concepts, establish a view of education and talent that meets the requirements of the times. The educational informationization also poses a challenge to the teacher's original role orientation. Teachers are required to relocate themselves and become reviewers and reflective persons. Education informatization has changed the traditional teacher-centered education model and transformed it into student-centered, personalized and cooperative learning. Teachers are no longer just "teachers" who complete the transmission of knowledge, but are designers and artists of teaching. Teachers should select appropriate teaching tools and design scientific and effective teaching activities according to teaching goals. The main responsibility of teachers should be changed from "teaching” to "leading”, from drawing questions to thinking and stimulating discussions, and finally guiding students to construct knowledge. Teachers should guide students to improve their information literacy and be the "masters" of information technology. They should learn to search, to analyze, to choose and conduct targeted learning in the complex ocean of information. Teachers also need to reflect constantly on themselves and on the teaching process to improve and adjust their own knowledge structure in time. In the teaching process, through evaluation and monitoring of the plan, implementation, feedback, and adjustment of various links, teachers can improve their professional development capabilities.

\section{The Level of Teachers' Information Education Technology and Comprehensive Iiteracy Needs to be Further Improved}

The progress of society, the development of information technology and the development of profession all require teachers to keep pace with the times. Teachers should be good at using information technology to learn new knowledge, develop new skills, and improve their overall quality. Teachers should have the capabilities guiding students to use information and multimedia technologies scientifically and reasonably to improve their learning efficiency. If students misuse them, negative effects will be caused, which will hinder their learning. The modern information technologies, such as cyberspace, MOOC platform, electronic courseware, multimedia teaching, distance education and computer-assisted teaching, have penetrated into all aspects of foreign language teaching, which bring great convenience for teaching, but also put forward newer and higher requirements for teachers' learning and innovation capabilities. Foreign language teachers need to learn new knowledge and techniques actively, constantly update their knowledge structure, expand their knowledge capacity. Teachers must master a certain degree of modern educational technology and improve their information literacy. "Information literacy refers to the ability of a person to recognize when they need information, to be able to retrieve, evaluate, and use information effectively, and to process, sort, refine, and innovate the acquired information to gain new knowledge." [6] The popularization of information technology and multimedia equipment makes students' learning approaches more diversified. This requires that foreign language teachers should not only possess professional knowledge and teaching methods, but also master the modern educational technology, otherwise they will not be able to guide students effectively.

\section{Conclusion}

The rapid development of modern information technology has facilitated the development of internet teaching and various online classrooms. It has played a huge role in promoting the efficiency and quality of teaching. The arrival of the information age requires that college English teachers(to be exact: all teachers) should keep up with the trend of the times and employ advanced teaching methods and research ideas to adjust to new teaching patterns and research development models. Only by adapting to the trend of the times and constantly improving their information literacy, can they grasp 
the tremendous opportunities brought about by information technology and promote the development of education modernization.

\section{Acknowledgement}

This research was financially supported by the Teaching and Research Project of Xi'an University of Technology, 2016: xjy1617.

\section{References}

[1] National Medium and Long-term Educational Reform and Development Program (2010-2020) http://education.news.cn/2010-07/29/c_12389320_2.htm, 2016-01-19.

[2] Department of Higher Education of the Ministry of Education, College English Curriculum Requirements, Foreign Language Teaching and Research Press, Beijing, 2007.

[3] Song-men, Shi. MOOC-based Research of College English Micro Lesson System, Journal of Jiangsu Open University, 25, (2014): 37-41.

[4] Yuan, Feng, Opportunities for and Challenges to Tertiary-Level FLT in the Light of E-Educology of Foreign Languages, CAFLE, 155, (2014.1): 76-80.

[5] Xiu-lin, Ma, Guo-qing, Zhao and Tong, Wu. An Empirical Study on the Influence of Flipped Classroom Model on Information Course Teaching, Journal of Distance Education, 2012(4).

[6] Jianlin, Chen. The Integration of Computer and Networks into Foreign Language Curriculum, Shanghai Foreign Language Education Press, Shanghai: 2010. 